\title{
Glycaemic index of different coconut (Cocos nucifera)-flour products in normal and diabetic subjects
}

\author{
Trinidad P. Trinidad ${ }^{1 *}$, Divinagracia H. Valdez ${ }^{1}$, Anacleta S. Loyola ${ }^{1}$, Aida C. Mallillin ${ }^{1}$, \\ Faridah C. Askali ${ }^{1}$, Joan C. Castillo ${ }^{1}$ and Dina B. Masa ${ }^{2}$ \\ ${ }^{1}$ Food and Nutrition Research Institute, Department of Science and Technology, Bicutan, Tagig, Metro Manila \\ 1631, Philippines \\ ${ }^{2}$ Philippine Coconut Authority, Department of Agriculture, Elliptical Road, Diliman, Quezon City, Philippines
}

(Received 2 October 2002 - Revised 16 May 2002 - Accepted 23 May 2003)

\begin{abstract}
The glycaemic index (GI) of commonly consumed bakery products supplemented with increasing levels of coconut (Cocos nucifera) flour was determined in ten normal and ten diabetic subjects. Using a randomized crossover design, the control and test foods were fed in random order on separate occasions after an overnight fast. Blood samples were collected through finger prick before and after feeding and were analysed for glucose levels using a clinical chemistry analyser. The significantly low-GI $(<60)$ foods investigated were: macaroons (GI 45.7 (SEM 3.0)) and carrot cake (GI 51.8 (SEM 3.3)), with 200-250 g coconut flour $/ \mathrm{kg}(P<0.05)$. The test foods with $150 \mathrm{~g}$ coconut flour/kg had GI ranging from 61.3 to 71.4. Among the test foods, pan de sal (GI 87.2 (SEM 5.5)) and multigrain loaf (GI 85.2 (SEM 6.8)) gave significantly higher GI with 50 and $100 \mathrm{~g}$ coconut flour/kg respectively $(P<0.05)$. On the other hand, granola bar and cinnamon bread with 50 and $100 \mathrm{~g}$ coconut flour $/ \mathrm{kg}$ respectively gave a GI ranging from 62.7 to 71.6 and did not differ significantly from the test foods with $150 \mathrm{~g}$ coconut flour $/ \mathrm{kg}(P<0.05)$. A very strong negative correlation $(r-0.85, n 11, P<0.005)$ was observed between the GI and dietary fibre content of the test foods supplemented with coconut flour. In conclusion, the GI of coconut flour-supplemented foods decreased with increasing levels of coconut flour and this may be due to its high dietary fibre content. The results of the present study may form a scientific basis for the development of coconut flour as a functional food. However, the fat content of coconut flour-supplemented food should always be considered to optimize the functionality of coconut fibre in the proper control and management of diabetes mellitus.
\end{abstract}

Glycaemic index: Coconut flour: Diabetes

Dietary guidelines recommend increased intake of dietary fibre for better control and proper management of chronic diseases such as diabetes mellitus, cardiovascular disease and cancer (Scientific Review Committee, Health and Welfare Canada, 1990; Food and Nutrition Research Institute, Department of Science and Technology, Philippines, 2000). The physical and chemical properties of dietary fibre, e.g. viscosity and fibrous structure, have an important role in the release and absorption of nutrients in the gastrointestinal tract. The glycaemic index (GI), a classification of food based on their blood glucose response relative to a starchy food, e.g. white bread, has been proposed as a therapeutic principle for diabetes mellitus by slowing carbohydrate absorption (Jenkins et al. 1982; Creutzfeldt, 1983). Low-GI food, e.g. food with added dietary fibre, has been shown to have reduced postprandial blood glucose and insulin responses and improved the overall blood glucose and lipid concentrations in normal subjects (Jenkins et al. 1987) and patients with diabetes mellitus (Collier et al. 1988; Fontvieille et al. 1988; Brand et al. 1991; Wolever et al. 1992). Our previous study has shown that coconut (Cocos nucifera) flour from coconut residue, a by-product of the coconut-milk industry, contained $600 \mathrm{~g}$ total dietary fibre $/ \mathrm{kg}$ (560 g insoluble and $40 \mathrm{~g}$ soluble fibre $/ \mathrm{kg}$; Trinidad et al. 2001). The present study aimed to determine the GI of coconut-flour products from normal and diabetic subjects. Results from the present study may form a scientific basis for the development of coconut flour as a functional food and in the production of coconut products in the Philippines.

\section{Materials and methods}

\section{Subjects}

Ten normal and diabetic (type 2) subjects were physically examined by a medical doctor and evaluated by an endocrinologist on the basis of the following criteria: normal subjects, BMI $20-25 \mathrm{~kg} / \mathrm{m}^{2}$, fasting blood glucose $4-7 \mathrm{mmol} / \mathrm{l}$, age 35-60 years, no physical defect and non-smokers; diabetic subjects, fasting blood glucose $7.5-11.0 \mathrm{mmol} / \mathrm{l}$, age 35-60 years, no intake of drugs, no complications

\footnotetext{
Abbreviation: GI, glycaemic index.

* Corresponding author: Dr Trinidad P. Trinidad, fax +63 2837 6149, email tpt@fnri.dost.gov.ph
} 
and non-smokers. Each subject was interviewed for assessment of physical activity levels and was asked to fill in a $3 \mathrm{~d}$ food intake recall form (Appendix). Subjects with normal food intake (pattern) and physical activity were included in the study. The diabetic subjects were managed through dietary consultations and advice. The subjects signed voluntary consent forms approved by the National Human Ethics Committee, Philippine Council for Health Research and Development, Department of Science and Technology, Metro Manila, Philippines.

\section{Test foods}

The control food was white bread prepared at the Nutrient Availability Laboratory, Food and Nutrition Research Institute, Department of Science and Technology, in a bread maker (KCTNO4584; Regal Kitchen Pro Collection, China) following the formulation of Wolever et al. (1994) as follows: $334 \mathrm{~g}$ flour (Wooden Spoon All Purpose Flour, Pillmico Mauri Food Corporation, Kwalan Cove, Iligan City, Philippines), $4 \mathrm{~g}$ salt, $5 \mathrm{~g}$ yeast, $7 \mathrm{~g}$ sucrose and $330 \mathrm{ml}$ water per $250 \mathrm{~g}$ carbohydrate loaf. Crust ends were not used for the test meals. The test foods with coconut flour were prepared at the Food Processing Division, Philippine Coconut Authority and Bakers Kingdom (Rustan's, Cubao, Quezon City, Metro Manila, Philippines) as follows (g coconut flour $/ \mathrm{kg}$ ): pan de sal 50, granola bar 50 , cinnamon bread 100 , multigrain loaf 100 , choco chip cookies 150, hotcake 150, choco crinkles 200, carrot cake 200, macaroons 250, brownies 250. The coconut flour was added to the all-purpose flour in the preparation of these bakery products (wet weight). The test foods were foods commonly eaten for breakfast and snacks. The test foods were all previously subjected to sensory evaluation, e.g. taste, appearance, and general acceptability.

\section{Protocol}

Using the randomized crossover design, the control and test foods were fed in random order on separate occasions after an overnight fast. The control and test foods contained $50 \mathrm{~g}$ available carbohydrates. The subjects were told to fast overnight $(10-12 \mathrm{~h})$ prior to the start of the study. Feeding of white bread was repeated three times while test foods were repeated twice. A standard glucose drink (Medic Orange 50 Glucose Tolerance Test Beverage Product no. 089 (50 g glucose $/ 240 \mathrm{ml})$; Medic Diagnostic Laboratory, Pasig City, Philippines) was given once to determine the relative GI of white bread.

Blood samples of approximately $0.3-0.4 \mathrm{ml}$ were collected through finger prick before and after feeding in a $4 \mathrm{~mm}$ diameter and $100 \mathrm{~mm}$ long capillary tubing (Pyrex; Corning, New York, USA) and sealed (Jockel Seal Sticks Cement, catalogue no. 2454 W15; AH Thomas, Pennsylvania, PA, USA). For normal subjects samples were collected at $0 \mathrm{~h}$ and every $15 \mathrm{~min}$ after feeding for $1 \mathrm{~h}$ and every $30 \mathrm{~min}$ for the next hour, while for diabetic subjects samples were collected at $0 \mathrm{~h}$ and at $30 \mathrm{~min}$ intervals after feeding for a period of $3 \mathrm{~h}$. The serum was separated from the blood using a refrigerated centrifuge after all the blood was collected (Eppendorf Centrifuge; Eppendorf,
Hamburg, Germany), and analysed for glucose levels on the same day using a clinical chemistry analyser (ARTAX Menarini Diagnostics, Florence, Italy) after calibration with the glucose standard (Glucofix Reagent 1; Menarini Diagnostics). The area under the glucose response curve for each food, ignoring the area below the fasting level, was calculated geometrically (Wolever et al. $1991 a, b)$. The GI of each food was expressed as \% mean glucose response of the test food divided by the standard food taken by the same subject and was determined by the following formula:

$$
\mathrm{GI}=\frac{\text { IAUC of the test food }}{\text { IAUC of the standard food }} \times 100,
$$

where IAUC is the incremental area under the glucose response curve.

\section{Analytical methods}

The test foods were analysed for moisture, ash, protein, fat and total dietary fibre using the methods of the Association of Official Analytical Chemists $(1984,1995)$ and Sullivan \& Carpenter (1993).

\section{Statistical analysis}

Differences between treatments and subjects were determined by two-way repeated-measures ANOVA and Duncan's multiple range tests. Correlation coefficients were determined to relate GI and the different nutrients present in the test foods. These statistical tests were carried out with the Statistical Analysis Systems program (SAS Institute Inc., Cary, NC, USA).

\section{Results}

Table 1 shows the characteristics of the subjects. The BMI of the normal subjects was 24.0 (SEM 1.2$) \mathrm{kg} / \mathrm{m}^{2}$ and the diabetic subjects 25.6 (SEM 1.6$) \mathrm{kg} / \mathrm{m}^{2}$. There were no significant differences between the normal and diabetic subjects for age and BMI. There were significant differences observed between subjects for the fasting blood glucose: the values for diabetic subjects were significantly greater than the normal subjects $(P<0 \cdot 05)$. Normal readings for the standard glucose used in the clinical chemistry analyser ranged from $4.0-6.4 \mathrm{mmol}$ glucose $/ 1$. The initial blood glucose obtained from the normal subjects for all test foods did not exceed $6.2 \mathrm{mmol}$ glucose $/ \mathrm{l}$. All of the

Table 1. Characteristics of the subjects (Mean values with their standard errors)

\begin{tabular}{|c|c|c|c|c|c|c|c|}
\hline \multirow[b]{2}{*}{ Subjects } & \multirow[b]{2}{*}{$n$} & \multicolumn{2}{|c|}{ Age (years) } & \multicolumn{2}{|c|}{ BMI $\left(\mathrm{kg} / \mathrm{m}^{2}\right)$} & \multicolumn{2}{|c|}{$\mathrm{FBG}(\mathrm{mmol} / \mathrm{l}$} \\
\hline & & Mean & SEM & Mean & SEM & Mean & SEM \\
\hline & 1 & 46. & 2 & $24.0^{a}$ & 1 & & \\
\hline Diabetic & 10 & $44.0^{a}$ & 2.4 & $25 \cdot 6^{a}$ & 1.6 & $8.9^{a}$ & 0.6 \\
\hline
\end{tabular}

FBG, Fasting blood glucose.

${ }^{a, b}$ Mean values within a column with unlike superscript letters were significantly different $(P<0.05)$ 
subjects were able to consume all test foods (white bread three times, test foods twice and standard glucose once; twenty-four occasions). The proximate analysis of coconut flour was as follows (per $\mathrm{kg}$ ): moisture 36, ash 31, fat 109, protein 121 , carbohydrate 703 . Coconut flour contained $600 \mathrm{~g}$ dietary fibre/kg (560 g insoluble and $40 \mathrm{~g}$ soluble/ $\mathrm{kg}$ ). All tests foods with coconut flour were analysed for fat, protein, and dietary fibre. Table 2 shows the nutrient content of the test foods fed to the subjects. There was an increasing trend in dietary fibre content of the test foods fed at increasing level of coconut flour-supplemented foods, with macaroons having a significantly greater dietary fibre content $(14.3$ (SEM 0.2$) \mathrm{g} / \mathrm{kg}, P<0.05)$ than the other test foods. As expected, white bread had a significantly lower dietary fibre content $(2.3$ (SEM $0 \cdot 1) \mathrm{g} / \mathrm{kg}$, $P<0.05)$ than the other test foods. On the other hand, macaroons had a significantly higher fat content $(33.5$ (SEM 0.8$) \mathrm{g} / \mathrm{kg}, \quad P<0.05$ ) among the test foods while white bread was significantly lower $(0.3$ (SEM $0 \cdot 1) \mathrm{g} / \mathrm{kg}$, $P<0.05)$. Pan de sal had a significantly higher protein content $(12 \cdot 1($ SEM $0 \cdot 1) \mathrm{g} / \mathrm{kg}, P<0 \cdot 05)$ while granola bar
(4.4 (SEM 0.1) g/kg, $P<0.05$ ) and choco chip cookies (4.4 (SEM 0.4) $\mathrm{g} / \mathrm{kg}, \quad P<0.05)$ had significantly lower protein content.

Table 3 shows the GI of the test foods. The GI of the standard white bread determined from the incremental area under the glucose response curve from white bread divided by the incremental area under the glucose response curve from the standard glucose was found to be 104 (SEM 4.0) and 105.0 (SEM 4.0) in normal and diabetic subjects respectively. The GI of all test foods did not differ significantly between normal and diabetic subjects except for choco crinkles (61.2 (SEM 5.4) and 77.0 (SEM 4.4) respectively). The significantly low GI $(<60)$ foods investigated were: macaroons (45.7 (SEM 3.0)) and carrot cake (51.8 (SEM 3.3)) (Table 3, Figs. 1 and 2), containing 200-250 g coconut flour $/ \mathrm{kg}(P<0 \cdot 05)$. The test foods with $150 \mathrm{~g}$ coconut flour $/ \mathrm{kg}$ had GI ranging from 61.3 to 71.4 .

Among the test foods, pan de sal (87.2 (SEM 5.5)) and multigrain loaf (85.2 (SEM 6.8)) had significantly higher GI (50 and $100 \mathrm{~g}$ coconut flour $/ \mathrm{kg}$ respectively, $P<0 \cdot 05$ ). On the other hand, granola bar and cinnamon bread with

Table 2. Nutrient content of test foods fed to subjects*

(Mean values with their standard errors)

\begin{tabular}{|c|c|c|c|c|c|c|c|c|}
\hline \multirow[b]{2}{*}{ Test foods } & \multirow[b]{2}{*}{ Coconut flour (g/kg) } & \multirow[b]{2}{*}{$\mathrm{CHO}(\mathrm{g})$} & \multicolumn{2}{|c|}{ Dietary fibre $(\mathrm{g})$} & \multicolumn{2}{|c|}{ Fat $(\mathrm{g})$} & \multicolumn{2}{|c|}{ Protein $(\mathrm{g})$} \\
\hline & & & Mean & SEM & Mean & SEM & Mean & SEM \\
\hline White bread & 0 & 50 & $2 \cdot 3^{f}$ & 0.1 & $0.3^{h}$ & 0.1 & $7 \cdot 3^{d}$ & 0.1 \\
\hline Pan de sal & 50 & 50 & $4 \cdot 5^{\mathrm{e}}$ & 0.4 & $2 \cdot 8^{f}$ & 0.1 & $12 \cdot 1^{a}$ & 0.1 \\
\hline Granola bar & 50 & 50 & $5 \cdot 8^{\mathrm{d}}$ & 0.2 & $9 \cdot 9^{d}$ & 0.1 & $4 \cdot 4^{\mathrm{g}}$ & 0.1 \\
\hline Cinnamon bread & 100 & 50 & $7 \cdot 3^{\mathrm{c}}$ & 0.2 & $14 \cdot 2^{\mathrm{C}}$ & 0.3 & $8 \cdot 5^{\mathrm{c}}$ & 0.4 \\
\hline Multigrain loaf & 100 & 50 & $7 \cdot 4^{\mathrm{c}}$ & 0.2 & $4.0^{\mathrm{e}}$ & 0.1 & $9 \cdot 8^{b}$ & 0.2 \\
\hline Choco chip cookies & 150 & 50 & $7 \cdot 5^{\mathrm{c}}$ & 0.1 & $9 \cdot 9^{d}$ & 0.7 & $4.4^{\mathrm{g}}$ & 0.4 \\
\hline Hotcake & 150 & 50 & $7 \cdot 4^{\mathrm{c}}$ & 0.9 & $1.5^{\mathrm{g}}$ & 0.3 & $9 \cdot 5^{\mathrm{b}}$ & 0.1 \\
\hline Choco crinkles & 200 & 50 & $8 \cdot 0^{\mathrm{bc}}$ & 1.1 & $9 \cdot 4^{d}$ & 0.8 & $4.7^{\mathrm{g}}$ & 0.3 \\
\hline Carrot cake & 200 & 50 & $10 \cdot 2^{\mathrm{b}}$ & 1.2 & $19 \cdot 3^{b}$ & 0.8 & $5 \cdot 9^{f}$ & 0.1 \\
\hline Macaroons & 250 & 50 & $14 \cdot 3^{\mathrm{a}}$ & 0.2 & $33 \cdot 5^{\mathrm{a}}$ & 0.8 & $7 \cdot 6^{\mathrm{d}}$ & 0.3 \\
\hline Brownies & 250 & 50 & $10 \cdot 5^{\mathrm{b}}$ & 0.3 & $15 \cdot 0^{\mathrm{C}}$ & 0.8 & $6 \cdot 3^{e}$ & 0.1 \\
\hline
\end{tabular}

$\mathrm{CHO}$, carbohydrate.

a,b,c,d,e,f,g Mean values with a column with unlike superscript letters were significantly different $(P<0.05)$

* Values are given on a freeze-dried basis.

Table 3. Glycaemic index of test foods in normal and diabetic subjects*

(Mean values with their standard errors for ten subjects per group)

\begin{tabular}{|c|c|c|c|c|c|}
\hline \multirow[b]{2}{*}{ Test foods } & \multirow[b]{2}{*}{ Coconut flour $(\mathrm{g} / \mathrm{kg})$} & \multicolumn{2}{|c|}{ Normal } & \multicolumn{2}{|c|}{ Diabetic } \\
\hline & & Mean & SEM & Mean & SEM \\
\hline Pan de sal & 50 & $87 \cdot 2^{a x}$ & $5 \cdot 5$ & $96 \cdot 6^{\mathrm{ax}}$ & $6 \cdot 1$ \\
\hline Granola bar & 50 & $65 \cdot 1^{\mathrm{bx}}$ & 4.9 & $71 \cdot 6^{\mathrm{bx}}$ & $4 \cdot 7$ \\
\hline Cinnamon bread & 100 & $62 \cdot 7^{\mathrm{bx}}$ & 4.2 & $71 \cdot 4^{\mathrm{bx}}$ & 4.9 \\
\hline Multigrain loaf & 100 & $85 \cdot 2^{a x}$ & $6 \cdot 8$ & $92 \cdot 5^{\mathrm{ax}}$ & 5.9 \\
\hline Choco chip cookies & 150 & $61 \cdot 3^{\mathrm{bx}}$ & 4.6 & $71 \cdot 4^{\mathrm{bx}}$ & $7 \cdot 3$ \\
\hline Hotcake & 150 & $65 \cdot 0^{\mathrm{bx}}$ & $3 \cdot 3$ & $72 \cdot 3^{\mathrm{bx}}$ & $5 \cdot 8$ \\
\hline Choco crinkles & 200 & $61 \cdot 3^{\mathrm{bx}}$ & $5 \cdot 4$ & $77 \cdot 0^{\text {by }}$ & 4.4 \\
\hline Carrot cake & 200 & $51 \cdot 8^{\mathrm{cX}}$ & $3 \cdot 3$ & $55 \cdot 0^{\mathrm{cx}}$ & $3 \cdot 7$ \\
\hline Macaroons & 250 & $45 \cdot 7^{\mathrm{cx}}$ & 3.0 & $46 \cdot 6^{\mathrm{dx}}$ & $3 \cdot 7$ \\
\hline Brownies & 250 & $60 \cdot 1^{\mathrm{bcx}}$ & $5 \cdot 4$ & $61 \cdot 3^{\mathrm{bcx}}$ & $5 \cdot 6$ \\
\hline
\end{tabular}




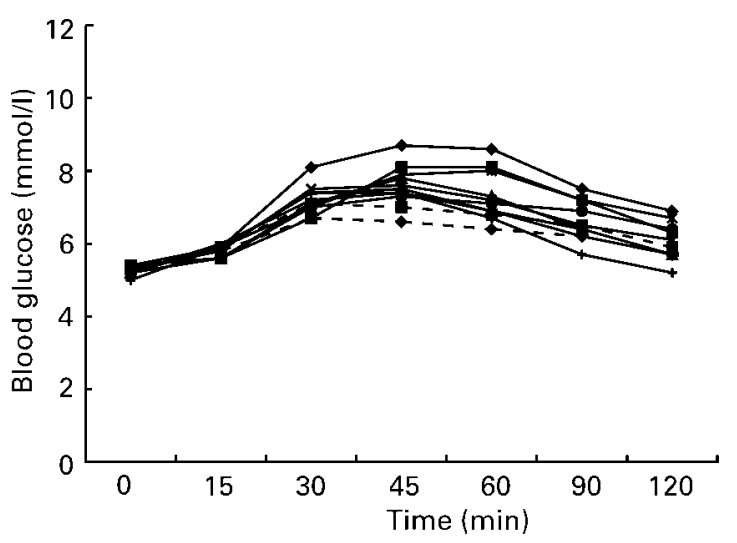

Fig. 1. Blood glucose response following coconut flour-supplemented products in normal subjects. $\bullet$, White bread; $\mathbf{\square}$, pan de sal; $\boldsymbol{\Lambda}$, granola bar; $\mathrm{X}$, cinnamon bread; $\star$, multigrain loaf; $\bullet$, choco chip cookie; +, hotcake; -, choco crinkles -, carrot cake; _macaroons; - - -, brownies. Values are means for ten subjects. For details of subjects, products and procedures, see Tables 1 and 2 and p. 552

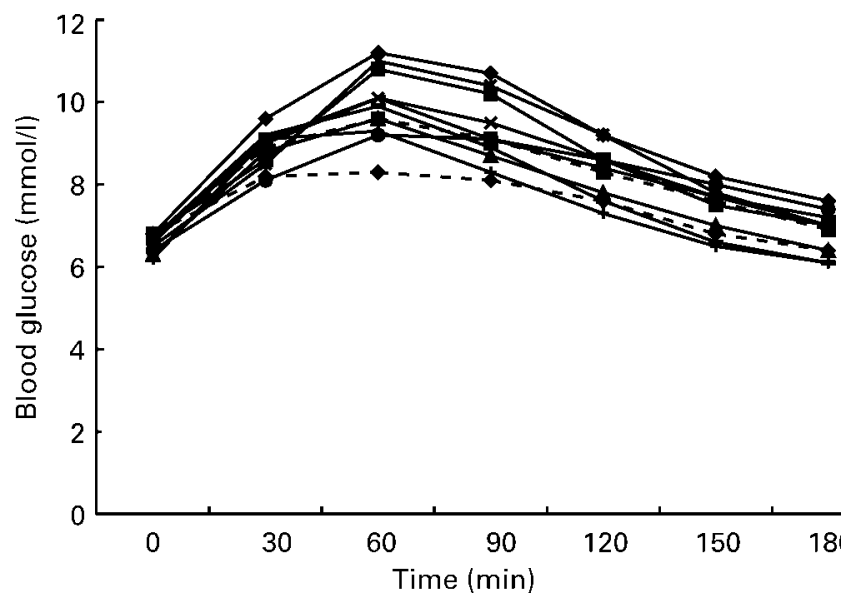

Fig. 2. Blood glucose response following coconut flour-supplemented products in diabetic subjects. $\bullet$, White bread; $\boldsymbol{\square}$, pan de sal; $\boldsymbol{\Lambda}$, granola bar; $\mathrm{X}$, cinnamon bread; $\star$, multigrain loaf; $\bullet$, choco chip cookie; + , hotcake; _, choco crinkles -, carrot cake; _ _ _, macaroons; - - -, brownies. Values are means for ten subjects. For details of subjects, products and procedures, see Tables 1 and 2 and p. 552.

50 and $100 \mathrm{~g}$ coconut flour/kg respectively gave GI ranging from 62.7 to 71.6 and did not differ significantly from the test foods with $150 \mathrm{~g}$ coconut flour $/ \mathrm{kg}(P<0 \cdot 05)$.

No significant correlation was found between the GI and the protein content of test foods fed to the subjects. We found a negative correlation between the GI and fat content of the test foods $(r-0.66, n 11, P<0 \cdot 05)$. A very strong negative correlation $(r-0.85, n 11, P<0.005)$ was observed between the GI and dietary fibre content of the test foods supplemented with coconut flour.

\section{Discussion}

The results of the present study showed that even at a constant amount of available carbohydrate in the test foods (50 $\mathrm{g}$ available carbohydrate), there was a significant variation in the GI, confirming that equi-carbohydrate portions of different foods may not necessarily have the same glycaemic effect in human subjects (Wolever et al. 1994). The blood glucose response may be influenced by insulin responses in the presence of protein (Nuttall et al. 1984; Simpson et al. 1985; Gannon et al. 1988), and differences in the rates of digestion and absorption influenced by the presence of dietary fibre, fat, cooking, anti-nutrients, particle size, food form and starch structure (Wursch, 1989; Wolever, 1990). The protein content of the test foods fed to the subjects ranged from 4.4 to $12.1 \mathrm{~g}$ (Table 2). According to several investigators (Nuttall et al. 1984; Simpson et al. 1985; Gannon et al. 1988), $20-30 \mathrm{~g}$ dietary protein is needed to increase insulin responses sufficiently to reduce glycaemic responses, especially in subjects with non-insulin-dependent diabetes mellitus. Therefore, the protein content of the test foods may not have any effect on the variability of GI in the test foods investigated.

A wide variability in fat content of the test foods ranging from 0.28 to $33.5 \mathrm{~g} / \mathrm{kg}$ was observed (Table 2 ). We do not believe that fat strongly affected the GI of the test foods investigated in the present study. There was only one test food that contained $>20 \mathrm{~g}$ fat $/ \mathrm{kg}$ in the study: macaroons (33.5 g fat $/ \mathrm{kg}$, Table 2). The amount of fat present in macaroons in the present study may not be sufficient enough to affect its overall glycaemic response, and similarly of the other test foods used in the study. In another study, it was shown that the addition of fat (about $23 \mathrm{~g}$ ) to a carbohydrate-based meal caused an early $(0-90 \mathrm{~min})$ decrease in glucose response; however, the overall glucose response was the same between the carbohydrate meal and the added-fat meal, suggesting that fat did not affect the overall glucose response to the food (Peters \& Davidson, 1993). The early decrease in the glucose response may be due to a delay in gastric emptying that may be mediated through an effect of fat on the duodenum and/or ileum (Welch et al. 1987). To further support the non-significant effect of fat on the GI of the test foods investigated in the present study, a multi-regression stepwise analysis using the SPSS statistical program was done to look at the interaction between GI and dietary fibre while controlling for fat content. A significant contribution of dietary fibre $(87.4 \%)$ in the variability of the GI from all test foods for both normal and diabetic subjects $(P<0.001)$ and a non-significant contribution from fat were obtained. This result also supported the corresponding low GI of the test foods at higher concentration of dietary fibre from coconut flour. Dietary fibre contributed to delaying the glycaemic responses of the coconut flour-supplemented food, a finding similar to previous work on dietary fibre and GI of foods (Jenkins et al. 1982; Welch et al. 1987; Peters \& Davidson, 1993). Moreover, purified soluble fibre reduces glycaemic responses to a greater extent than purified insoluble fibre (Jenkins et al. 1978). Considering the dietary fibre present in whole foods, insoluble fibre was related more strongly to the GI than soluble fibre content (Jenkins et al. 1989). Coconut flour contains $600 \mathrm{~g}$ total dietary fibre $/ \mathrm{kg}$ (560 g insoluble and $40 \mathrm{~g}$ soluble/kg; Trinidad et al. 2001).

The significant differences between the GI of choco crinkles in normal and diabetic subjects is difficult to explain. The differences in glucose responses between the two 
groups may be due to rates of digestion and absorption in relation to the food ingested.

In conclusion, the GI of coconut flour-supplemented foods decreased with increasing levels of coconut flour and this effect may be due to its high dietary fibre content. The fat content of the test foods may have little or no effect on the GI of the test foods investigated. The results of the present study may form a scientific basis for the development of coconut flour as a functional food. However, the fat content of coconut-supplemented foods should always be considered in order to optimize the functionality of coconut fibre in the proper control and management of diabetes mellitus.

\section{Acknowledgements}

The authors wish to thank Professor Thomas M. S. Wolever, Department of Nutritional Sciences, University of Toronto, Toronto, Canada, for personal consultations regarding the calculation of the GI of the standard and test foods. The authors also wish to thank Zoilo B. Villanueva, Adorie D. Sabenecio, Josefina A. Desnacido and Revelita L. Cheong of the Nutritional Biochemistry Section, Food and Nutrition Research Institute, Department of Science and Technology for their technical assistance, and Ms Ana Marie Tumbokon of the Food Processing Division, Philippine Coconut Authority and the Bakers Kingdom, Rustan's Cubao, Quezon City, Metro Manila, for the preparation of food samples. This project would not have been possible without the support from the Philippine Council for Health Research and Development, Department of Science and Technology and the Philippine Coconut Authority, Department of Agriculture.

\section{References}

Association of Official Analytical Chemists (1984) Official Methods of Analysis, 14th ed., pp. 249 and 251, Arlington, VA: AOAC

Association of Official Analytical Chemists (1995) Official Methods of Analysis, Suppl. p. 991.43, Arlington, VA: AOAC.

Brand JC, Calagiuri S, Crossman S, Allan A, Roberts DCK \& Truswell AS (1991) Low glycemic index foods improve long-term glycemic control in NIDDM. Diabetes Care 14, 95-101.

Collier GR, Giudici S, Kalmusky J, et al. (1988) Low glycemic index starchy foods improve glucose control and lower serum cholesterol in diabetic children. Diabetes Nutr Metab 1, 1-9.

Creutzfeldt W (1983) Introduction. In Delaying Absorption as a Therapeutic Principle in Metabolic Diseases, p. 1 [W Creutzfeldt and RU Folsch, editors]. New York: Thiem-Stratton.

Fontvieille AM, Acosta M, Rizkalla SW, et al. (1988) A moderate switch from high to low glycemic index foods for three weeks improves the metabolic control of type I (IDDM) diabetic subjects. Diabetes Nutr Metab 1, 139-143.

Food and Nutrition Research Institute (2000) Dietary Guidelines for Filipinos, revised ed. Metro Manila, Philippines: Department of Science and Technology.
Gannon MC, Nuttall FD, Neil BJ \& Westphal SA (1988) The insulin and glucose response to meals of glucose plus various proteins on type II diabetic subjects. Metabolism 37, $1081-1088$

Jenkins DJA, Cuff D \& Wolever TMS (1987) Digestibility of carbohydrate foods in an ileostomate: relationship to dietary fiber, in vitro digestibility and glycemic response. Am J Gastroenterol 82, 709-717.

Jenkins DJA, Ghafari A, Wolever TMS, et al. (1982) Relationship between the rate of digestion of foods and post-prandial glycemia. Diabetologia 22, 450-455.

Jenkins DJA, Wolever TMS, Leeds AR, et al. (1978) Dietary fibres, fibre analogues and glucose tolerance: importance of viscosity. Br Med J 2, 1744-1746.

Jenkins DJA, Wolever TMS, Vuksan V, et al. (1989) "Nibbling versus Gorging": Metabolic advantages of increased meal frequency. New Engl J Med 321, 929-934.

Nuttall FD, Mooradian AD, Gannon MC, Billington C \& Krezowski P (1984) Effect of protein ingestion on the glucose and insulin response to a standardized oral glucose load. Diabetes Care 7, 465-470.

Peters AL \& Davidson MB (1993) Protein and fat effects on glucose response and insulin requirements in subjects with insulin-dependent diabetes mellitus. Am J Clin Nutr 58, 555-560.

Scientific Review Committee, Health and Welfare Canada (1990) Nutrition Recommendations. Ottawa: Canadian Government Publishing Center.

Simpson RW, McDonald J, Wahlqvist ML, Atley L \& Outch K (1985) Macronutrients have different metabolic effects in non-diabetics and diabetics. Am J Clin Nutr $\mathbf{4 2}$, 449-453.

Sullivan DM \& Carpenter DE, (editors) (1993) Methods of Analysis for Nutrition Labeling, p. 402. Gaitherberg, MD: AOAC International.

Trinidad TP, Valdez DH, Mallillin AC, Askali FC, Chua M \& Maglaya A (2001) Coconut Flour from Coconut Residue: a Promising Functional Food. Proceedings of the 37th COCOTECH Meeting, July 17-21, Ho Chi Minh City, Vietnam Jakarta, Indonesia: Asia and Pacific Coconut Community.

Welch IM, Bruce C, Hill SE \& Read NW (1987) Duodenal and ileal lipid suppresses postprandial blood glucose and insulin responses in man: possible implications for the dietary management of diabetes mellitus. Clin Sci 72, 209-216.

Wolever TMS (1990) The glycemic index. In Aspects of Some Vitamins, Minerals and Enzymes in Health and Disease, [GH Bourne, editor]. World Rev Nutr Diet 62, 120-185.

Wolever TMS, Jenkins DJA, Jenkins AL \& Josse RG (1991a) The glycemic index: methodology and clinical implications. Am J Clin Nutr 54, 846-854.

Wolever TMS, Jenkins DJA, Vuksan V, Jenkins AL, Wong GS \& Josse RG (1991b) Beneficial effect of low glycemic index diet in overweight NIDDM subjects. Diabetes Care 15, $562-566$.

Wolever TMS, Jenkins DJA, Vuksan V, et al. (1992) Beneficial effect of a low glycemic index diet in type 2 diabetes. Diabetes Med J 9, 451-458.

Wolever TMS, Katzman-Relle L, Jenkins JL, Vuksan V, Josse RG \& Jenkins DJA (1994) Glycemic index of 102 complex carbohydrate foods in patients with diabetes. Nutr Res 14, 651-669.

Wursch P (1989) Starch in human nutrition. In Nutritional Value of Cereal Products, Beans and Starches [GH Bourne, editor]. World Rev Nutr Diet 60, 199-256. 


\section{Appendix}

Food record

Subject's name:

Date (month-d-year) 